\title{
ACQUIRED MEGACOLON AS A COMPLICATION OF RECTO-SIGMOIDECTOMY FOR HIRSCHSPRUNG'S DISEASE*
}

\author{
BY
}

\author{
TH. EHRENPREIS \\ From the Children's Clinic, Karolinska Sjukhuset, Stockholm, Sweden
}

Acquired megacolon, or aperistalsis of the colon and/or rectum, is a common disease in adults in certain rural areas of South America. It is often associated with mega-oesophagus. At times other parts of the digestive tract, the urinary tract, or the heart are involved. These are advanced phases of a systemic disease (Chagas' disease), caused by Trypanosoma cruzi. The underlying pathology is a lesion of the intramural ganglion cells, which results in degeneration (Hurst, 1925; Etzel, 1937) and a reduction in number of ganglion cells (Köberle, 1956).

Acquired megacolon is practically unknown outside South America. A recent observation of a Swedish case that fulfils the clinical and histological criteria for a diagnosis of 'acquired megacolon' seems to be of interest, though the aetiology is obviously different from the South American type of aperistalsis.

\section{Case Report}

A 21-year-old girl was admitted in 1959 with typical symptoms and signs of a short-segment Hirschsprung's disease (Fig. 1). A Swenson procedure was performed, the resection including 6-7 $\mathrm{cm}$. of dilated bowel proximal to the transition zone and leaving $2-3 \mathrm{~cm}$. of the anal canal behind. The length of the resected narrow segment was $7 \mathrm{~cm}$. The specimen showed aganglionosis distally and normal findings proximally. The post-operative course was uneventful but no improvement of the patient's constipation occurred. After 6 weeks, a sphincterotomy was performed. A slight improvement was noted that soon proved to be temporary. Constipation continued and the bowels had to be cleared by an enema every second or third day. Moderate abdominal distension persisted and the child failed to thrive. She was readmitted in March 1964 at the age of 6 years. Barium enema (Fig. 2) revealed a magnificent megacolon with a narrow segment extending to the level of the promontory. The anastomosis performed at the first operation was

\footnotetext{
* A paper read at a meeting of the British Association of Paediatric Surgeons in Rotterdam, September 1964.
}

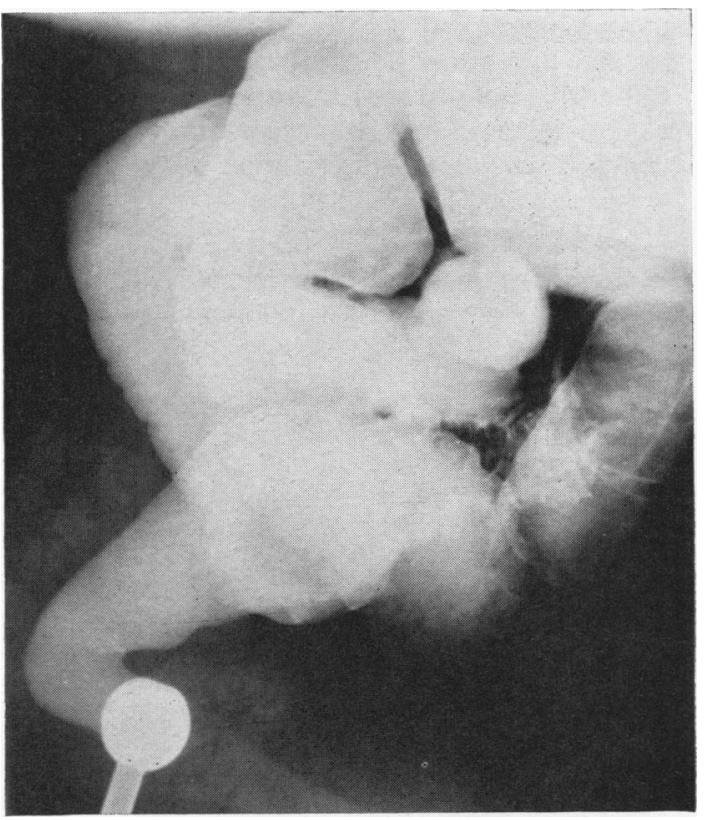

FIG. 1.-Pre-operative barium enema, showing short-segment Hirschsprung's disease.

barely palpable $4 \mathrm{~cm}$. from the anal opening. A secondary resection was performed with a subsequent oblique anastomosis according to Grob's latest modification of the Swenson and Duhamel procedures. The length of the resected narrow segment was $15 \mathrm{~cm}$. The postoperative course was uneventful. The patient has been completely relieved of her constipation so far, though the follow-up period has been only three months.

Microscopic examination of the resected specimen showed normal findings proximally. Throughout the entire narrow segment ganglion cells were sparse and showed degenerative changes (Fig. 3). The blood vessels showed inclusions of hyaline material in their walls (Fig. 4). 


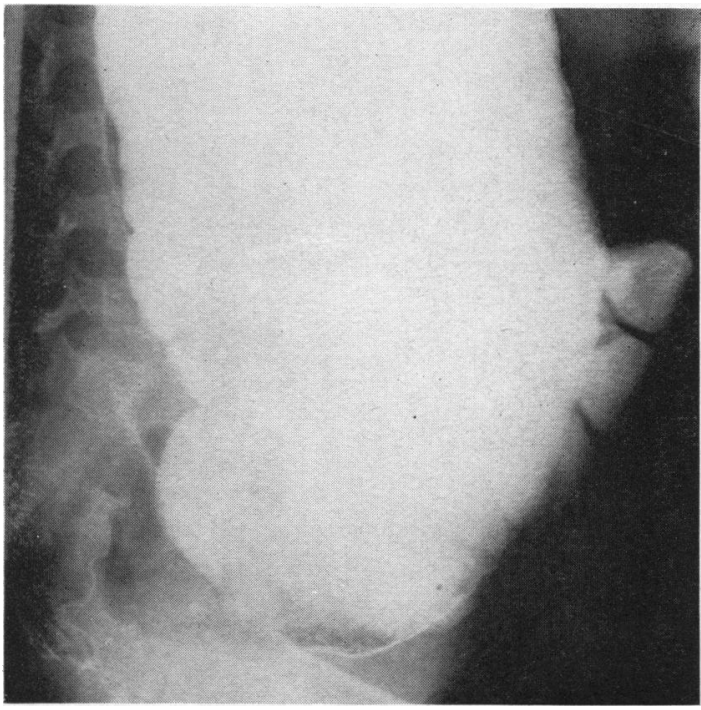

FIG. 2.-Barium enema $3 \frac{1}{2}$ years after recto-sigmoidectomy, showing pronounced megacolon with a recurrent narrow segment.

The interesting feature in this case is the persistence of constipation and the recurrence of a narrow segment after radical excision of the original aganglionic segment. The secondary narrow segment was much longer than that seen originally and could obviously not have been the result of growth of the $2-3 \mathrm{~cm}$. of the anal canal that were left at the first operation. The primary anastomosis could be identified within the distal part of the secondary narrow segment.

The clue to the pathogenesis of the secondary narrow segment lies in the histological findings in the specimen removed at the second 'recto-sigmoidectomy'. As far as can be judged without personal experience of the South American type of acquired megacolon, the histological findings in this specimen are in good agreement with the description given by South American authors. It is, however, highly improbable that the aetiology could be similar. It would seem more likely that the degenerative changes in the myenteric plexus, as well as the hyaline vascular inclusions found in the present case, were caused by some unnoticed impairment to the vascular supply of the bowel segment which had been mobilized and pulled through at the primary rectosigmoidectomy. If so, this vascular disturbance had been just severe enough to cause degeneration of the ganglion cells (which are probably more sensitive to such disturbances than other elements of the bowel wall) without compromising the vitality of the bowel itself. These assumptions are borne out by reports of experimentally-produced megacolon with degeneration or total destruction (depending on experimental conditions) of the intracolonic plexuses after injection of Urokon into the left colic artery (McElhannon, 1960) and after temporary occlusion

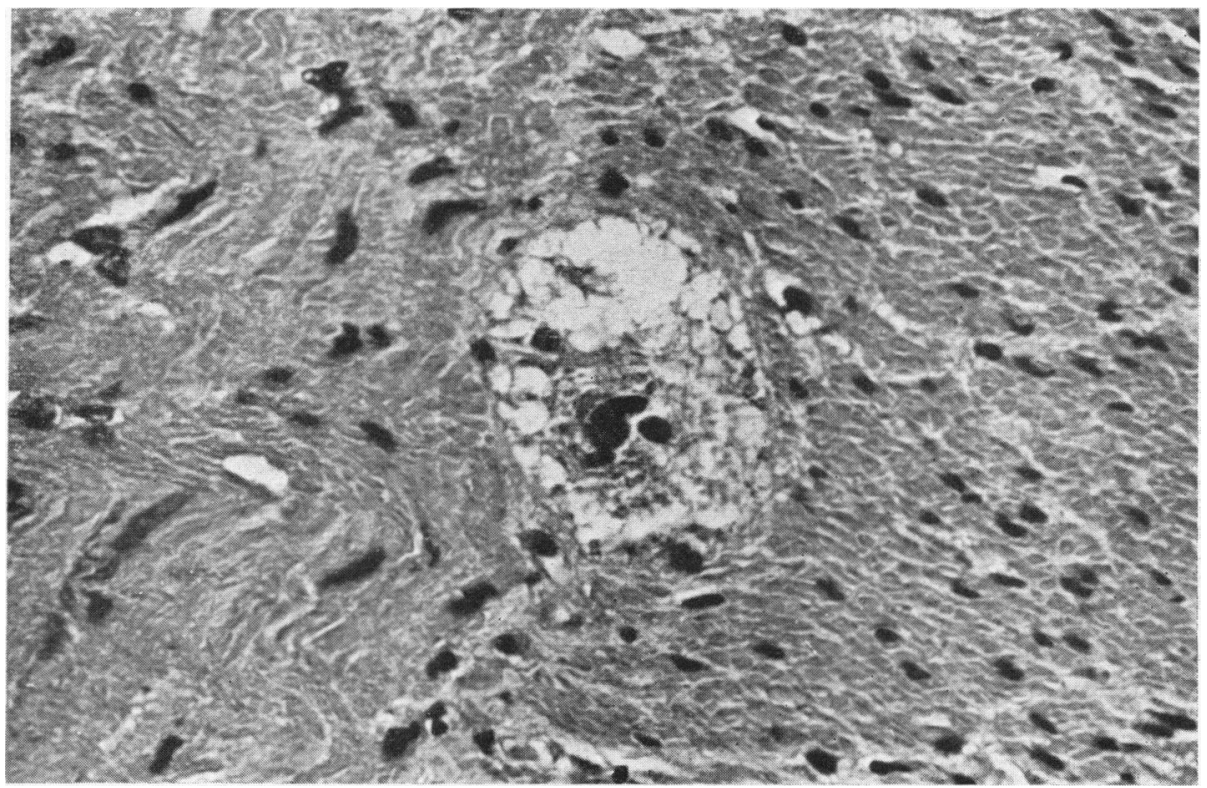

Fig. 3.-Microphotograph of recurrent narrow segment, showing degenerative changes of ganglion cell. $(\times 700$. 


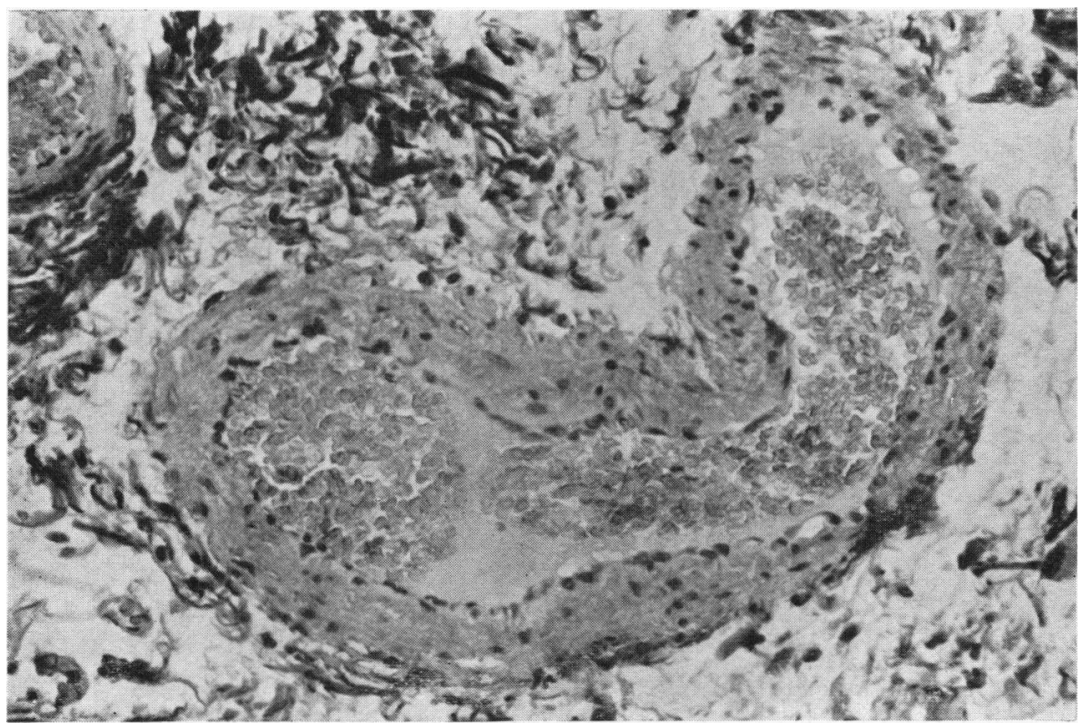

FIG. 4.-Microphotograph of recurrent narrow segment, showing hyaline inclusions in the wall of the blood vessel. ( $\times 50$.)

of the inferior mesenteric artery (Hukuhara, Kotani, and Sato, 1961).

This type of complication has not been encountered previously in more than 100 recto-sigmoidectomies, performed personally, nor have any published reports on similar complications been found. This is remarkable considering the large number of rectosigmoidectomies that have been done during the past 15 years.

\section{Summary}

The case is described of a $2 \frac{1}{2}$-year-old child with Hirschsprung's disease, who, following a rectosigmoidectomy, developed a severe degree of megacolon. This was considered to have resulted from impairment of the vascular supply to the colon at the time of operation, causing degeneration of the ganglion cells.

\section{REFERENCES}

Etzel, E. (1937). Megaoesophagus and its neuropathology: a clinical and anatomo-pathological research. Guy's Hosp. Rep., 87, 158.

Hukuhara, T., Kotani, S., and Sato, G. (1961). Effects of destruction of intramural ganglion cells on colon motility: possible genesis of congenital megacolon. Jap. J. Physiol., 11, 635.

Hurst, A. F. (1925). The sphincters of the alimentary canal and their clinical significance. Brit med.J., 1, 145.

Köberle, F. (1956). Zur Frage der Entstehung sog. "idiopathischer Dilatationen" muskulärer Hohlorgane. Virchows Arch. path. Anat., 329, 337.

McElhannon, F. M. (1960). Experimental production of megacolon resembling Hirschsprung's disease. Surg. Forum, 10, 218. 